\title{
Efficacy of interventions to reduce coercive treatment in mental health services: umbrella review of randomised evidence
}

Corrado Barbui, Marianna Purgato, Jibril Abdulmalik, José Miguel Caldas-de-Almeida, Julian Eaton, Oye Gureje, Charlotte Hanlon, Michela Nosè, Giovanni Ostuzzi, Benedetto Saraceno, Shekhar Saxena, Federico Tedeschi and Graham Thornicroft

\section{Background}

Coercive treatment comprises a broad range of practices, ranging from implicit or explicit pressure to accept certain treatment to the use of forced practices such as involuntary admission, seclusion and restraint. Coercion is common in mental health services.

\section{Aims}

To evaluate the strength and credibility of evidence on the efficacy of interventions to reduce coercive treatment in mental health services. Protocol registration: https://doi.org/10.17605/ OSF.IO/S76T3.

\section{Method}

Systematic literature searches were conducted in MEDLINE, Cochrane Central, PsycINFO, CINAHL, Campbell Collaboration, and Epistemonikos from January 2010 to January 2020 for metaanalyses of randomised studies. Summary effects were recalculated using a common metric and random-effects models. We assessed between-study heterogeneity, predictive intervals, publication bias, small-study effects and whether the results of the observed positive studies were more than expected by chance. On the basis of these calculations, strength of associations was classified using quantitative umbrella review criteria, and credibility of evidence was assessed using the GRADE approach.

\section{Results}

A total of 23 primary studies (19 conducted in European countries and 4 in the USA) enrolling 8554 participants were included. The evidence on the efficacy of staff training to reduce use of restraint was supported by the most robust evidence (relative risk $\mathrm{RR}=0.74,95 \% \mathrm{Cl}$ 0.62-0.87; suggestive association, GRADE: moderate), followed by evidence on the efficacy of shared decision-making interventions to reduce involuntary admissions of adults with severe mental illness ( $R R=0.75,95 \% \mathrm{Cl} 0.60-0.92$; weak association, GRADE: moderate) and by the evidence on integrated care interventions ( $R R=0.66,95 \% \mathrm{Cl} 0.46-0.95$; weak association, GRADE: (ow). By contrast, community treatment orders and adherence therapy had no effect on involuntary admission rates.

\section{Conclusions}

Different levels of evidence indicate the benefit of staff training, shared decision-making interventions and integrated care interventions to reduce coercive treatment in mental health services. These different levels of evidence should be considered in the development of policy, clinical and implementation initiatives to reduce coercive practices in mental healthcare, and should lead to further studies in both high- and low-income countries to improve the strength and credibility of the evidence base.

\section{Keywords}

Coercive treatment; involuntary admissions; restraint use; metaanalysis; community treatment order.

\section{Copyright and usage}

(c) The Author(s), 2020. Published by Cambridge University Press. This is an Open Access article, distributed under the terms of the Creative Commons Attribution licence (http://creativecommons. org/licenses/by/4.0/), which permits unrestricted re-use, distribution, and reproduction in any medium, provided the original work is properly cited.
The use of coercion is common in formal and non-formal settings, ${ }^{1,2}$ including mental health services. ${ }^{3}$ Coercive treatment comprises a broad range of practices, ranging from implicit or explicit pressure to accept certain treatment to the use of forced practices such as involuntary admission, seclusion and different forms of restraint. ${ }^{4}$ Available epidemiological data suggest wide variations in the rates of involuntary admissions across countries, local areas and services, ${ }^{5}$ with rates increasing over time in some countries. ${ }^{6}$ In England, for example, the rate of involuntary psychiatric hospital admission has increased by more than one-third in the past 6 years, and in Scotland the number of detentions has increased by $19 \%$ in the past 5 years. ${ }^{7}$ In The Netherlands, in the period 2003-2017 the rate of treated requests for court-ordered involuntary admissions increased from 44 to 64 per 100000 population. ${ }^{8,9}$ Involuntarily admitted people may also be exposed to further coercive measures during hospital admissions, such as seclusion, administration of medication against their will and restraint, but the frequency and severity of these multiple forms of coercion are still poorly understood. ${ }^{1-4}$
Coercive treatment conflicts with the principle of autonomy, a central guiding principle of the Convention on the Rights of Persons with Disabilities (CRPD), which aims to empower mental health patients in making their own decisions about treatment. ${ }^{10,11}$ In addition to human rights considerations, empirical data suggest that coercive practices may be a traumatising experience leading to profound loss of trust in the therapeutic relationship and to physical health problems such as skin injuries, neurological problems, pulmonary disease, deep vein thrombosis and even death. ${ }^{12,13}$ Coercion can also have long-term adverse consequences in terms of service avoidance, with reduced access to mental healthcare. ${ }^{14}$

Against this background, during recent decades strategies and interventions have been developed to reduce the use of coercion, simultaneously attempting to preserve the right of people with mental health conditions to receive effective treatments, including when they may be less able to express their own will and preferences. ${ }^{4,15}$ However, the efficacy of these interventions is controversial, and the evidence fragmented into several reviews focusing on 
different populations, interventions and outcomes, leading some to conclude that there is very little research in this area. ${ }^{3}$ Consequently, most evidence-based guidelines for mental health conditions do not consider measures to reduce coercion.

Therefore, the aim of this umbrella review was to summarise the efficacy of interventions to reduce the use of coercive care in mental health services. Effect sizes for interventions were re-analysed using quantitative umbrella review criteria in order to accurately quantify the strength of associations, and credibility of evidence was assessed using the Grading of Recommendations Assessment, Development and Evaluation (GRADE) approach. ${ }^{16-18}$

\section{Method}

\section{Study design}

We employed an umbrella review methodology to systematically review all available reviews on the topic. Umbrella review is a term applied to systematic overviews of systematic reviews and meta-analyses. ${ }^{19-22}$ This review methodology was chosen as it provides an overall picture of an important area of healthcare and it can highlight whether the evidence base is consistent or contradictory. ${ }^{23}$ In clinical areas with multiple interventions for the same condition, or with multiple populations for similar interventions, and with several clinically relevant outcomes, umbrella reviews may provide quantitative syntheses of the beneficial effects of interventions for different populations and outcomes using a common metric. $^{21-23}$ A review protocol was registered in the Open Science Framework platform: https://doi.org/10.17605/OSF.IO/S76T3.

\section{Types of systematic review included}

Systematic reviews of randomised studies investigating the efficacy of interventions to reduce coercive treatment for people with mental health conditions in any treatment setting were included. Interventions included any type of non-pharmacological strategies aiming to reduce the use of coercive measures such as involuntary admissions or use of physical restraint. Mental health conditions included any mental health problem along a continuum from mild, time-limited psychological distress to long-term and severely disabling conditions. ${ }^{24}$

Only systematic reviews with a quantitative synthesis of trial results (meta-analysis) were retained. Similarly, systematic reviews without study-level effect sizes and 95\% confidence intervals (CIs) were excluded. When two systematic reviews presented overlapping data-sets, the one with the largest number of component studies providing study-level effect sizes was retained for the main analysis, in agreement with umbrella review methodology. ${ }^{19,22}$ References of primary studies from all identified meta-analyses were inspected to cross-check whether relevant primary studies were missed by the included systematic reviews.

\section{Literature search, systematic review selection and data extraction}

MEDLINE, PubMed, Cochrane Central, PsycINFO, CINAHL, Epistemonikos and Campbell Collaboration databases were searched from January 2010 to January 2020. The following terms were used: (coercio* ${ }^{*}$ Title/Abstract] OR involunt ${ }^{*}[$ Title/Abstract] OR restraint ${ }^{\star}\left[\right.$ Title/Abstract] OR seclusion ${ }^{*}$ [Title/Abstract] OR compulsory $^{\star}[$ Title/Abstract]) AND (meta-analysis[Publication Type] OR meta-analysis[Title/Abstract] OR meta-analysis[MeSH Terms] OR systematic[Title/Abstract] OR review[Title/Abstract]). The complete search strategy is provided in the supplementary material, available at https://doi.org/10.1192/bjp.2020.144. The search was restricted to the past 10 years to provide an up-to-date overview of the evidence. ${ }^{22}$ No language restrictions were applied. Electronic database searches were supplemented by a manual search of reference lists from relevant studies. The Preferred Reporting Items for Systematic Reviews and Meta-Analyses reporting standards (PRISMA) were followed to document the process of systematic review selection. ${ }^{25}$

The selection of potentially relevant systematic reviews was made by carefully inspecting titles and abstracts. This was done by two reviewers independently (C.B., M.P.). In case of discrepancies, a third review author (G.O.) was involved and consensus reached by discussion. When titles and abstracts did not provide information on the inclusion and exclusion criteria, the full articles were obtained to verify eligibility. The full texts of potentially included systematic reviews were obtained and carefully appraised by at least two reviewers. The reference lists of included articles were analysed for additional items not retrieved by the database searches.

From each included systematic review, two investigators (C.B., M.P.) independently extracted information on first author, year of publication, outcomes, number of included studies and reported summary meta-analytic estimates. The following information was extracted from each primary study: year of publication, mental health condition, type of intervention, outcomes, sample size and study-specific effect size with the corresponding $95 \%$ confidence interval.

\section{Reporting quality of included systematic reviews}

The quality of included systematic reviews was independently assessed by two reviewers (C.B., M.P.) using AMSTAR 2 (A Measurement Tool to Assess Systematic Reviews), a 16-point assessment tool of the methodological quality of systematic reviews. ${ }^{26}$ AMSTAR 2 has good interrater agreement, test-retest reliability and content validity (supplementary material). ${ }^{26}$

\section{Statistical analysis}

Summary relative risks (RR) with $95 \%$ confidence intervals were re-estimated using common metrics and random-effects models because we were expecting heterogeneity. ${ }^{27}$ To produce a pragmatic measure of the efficacy of interventions, numbers needed to treat (NNTs) were calculated using the formulae provided by Furukawa. ${ }^{28} \mathrm{We}$ also estimated the $95 \%$ prediction interval (PI) for the summary random-effects estimates. ${ }^{29}$ Prediction intervals further account for heterogeneity between studies and specify the uncertainty for the effect that would be expected in a new study examining that same research question. ${ }^{29}$ Heterogeneity was evaluated with Cochran's $Q$ statistic $^{30}$ (statistically significant for $P<0.10$ ) and quantified with the $I^{2}$ metric. ${ }^{31}$ Egger's test was used to evaluate potential publication and small-study effects biases. ${ }^{32,33}$ In particular, $P \leq 0.10$ in the regression asymmetry test with a more conservative effect in the largest study was considered evidence for small-study effects bias.

We further evaluated the excess significance, which is a test that examines whether the observed number of studies $(O)$ with statistically significant results (positive studies, $P<0.05$ ) in each meta-analysis is larger than their expected number $(E) .{ }^{34}$ For each metaanalysis, $E$ was calculated as the sum of the statistical power estimates for each study in the meta-analysis. The power of each study was calculated by an algorithm using a non-central $t$-distribution. ${ }^{35}$ The estimated power depends on the plausible effect size. As the true effect size for any meta-analysis is unknown, we assumed that the most plausible effect is given by the largest study. Excess significance for each meta-analysis was claimed at the $P \leq 0.10$ level. $^{34}$

On the basis of these calculations, we classified the strength of each association as 'convincing', 'highly suggestive', 'suggestive' or 
'weak' (supplementary material). ${ }^{21,22,36,37}$ Specifically, meta-analyses were free from biases (convincing, class I) if they met the following criteria: $P<10^{-6}$ based on random effects meta-analysis; $>1000$ participants; low or moderate between-study heterogeneity $\left(I^{2}<50 \%\right)$; $95 \%$ PI that excluded the null value; no evidence of small-study effects and excess significance; largest study nominally significant $(P<0.05)$. Highly suggestive association (class II) criteria required $>1000$ participants, highly significant summary associations $\left(P<10^{-6}\right.$ by random-effects models) and largest study nominally significant $(P<0.05)$. Suggestive evidence (class III) criteria required only $>1000$ participants and $P \leq 0.001$ by random-effects models. Weak association (class IV) criteria required only $P \leq$ 0.05 . Associations were considered non-significant if $P$ was $>0.05$. Statistical analyses and power calculations were performed using Stata version 15.0 for Windows (Stata Corp, College Station, TX, USA). $P$-values were all two-tailed.

In addition to these quantitative criteria, the overall credibility of the estimates was qualitatively assessed by two reviewers (C.B., M.P.) using the GRADE method (supplementary material). ${ }^{17,18,38,39}$ GRADE allows the credibility of estimate for each outcome to be rated and supplies a tabular overview of findings easily understandable for intervention participants, policy makers, research planners, guideline developers and other interested stakeholders. ${ }^{17}$ Summary of findings tables were developed using GRADEPro GDT.

\section{Results}

\section{Description of included systematic reviews}

The systematic search yielded 6821 records. After duplicate removal and inspection of titles and abstracts, 77 full-text articles were assessed for eligibility. Of these, 67 were excluded for the reasons reported in the supplementary material, and 10 systematic reviews with a quantitative synthesis of trial results were identified and critically appraised with AMSTAR 2 (Fig. 1). ${ }^{40-49}$ From these ten systematic reviews we retained and included in statistical re-analysis the three non-overlapping systematic reviews with the largest number of component studies (Fig. 1 and supplementary material). ${ }^{43,47,48}$ These 3 systematic reviews provided data on 5 meta-analyses, including 23 randomised studies, 24 comparisons and 8554 participants. ${ }^{50-72}$

In terms of populations, four meta-analyses included participants with severe mental illness and one analysed studies with participants with cognitive decline or dementia (Table 1). In terms of interventions, four meta-analyses assessed the efficacy of the following interventions to reduce involuntary admissions: shared decision-making interventions (including advance statements, crisis cards and patient-held information strategies); community treatment orders; adherence-enhancement interventions; or integrated care interventions (Table 1). One meta-analysis assessed the efficacy of staff training to reduce use of physical restraint (Table 1). All studies were conducted in high-income countries.

\section{Quality assessment of the included systematic reviews}

AMSTAR 2 was used to describe the methodological characteristics of the ten systematic reviews with a quantitative synthesis of trial results, including the three systematic reviews that contributed to the analysis (supplementary material). Two of the three included systematic reviews did not have a review protocol, and none of the three provided a list of excluded studies. In addition, the funding source of the primary studies was not reported (supplementary material). Otherwise, the three systematic reviews performed well in terms of quality of the search strategy, risk of bias, heterogeneity and publication bias assessment (supplementary material).

\section{Summary effect sizes}

Re-analysis of the five meta-analyses assessing the efficacy of interventions to reduce involuntary admissions and use of restraint is shown in Fig. 2, and the number of included studies and participants, as well as the main characteristics of each meta-analysis, are reported in Table 2. For the outcome of involuntary admissions, only the meta-analyses of the efficacy of shared decision-making interventions and integrated care reported a statistically significant $(P \leq 0.05)$ summary effect using random-effects models. Similarly, for the outcome of use of restraint, the meta-analysis on the efficacy of staff training interventions reported a statistically significant summary effect $(P \leq 0.05)$ (Table 2$)$. Of these three meta-analyses, a significance threshold below $10^{-3}$ was reached by the meta-analyses of staff training interventions, but a significance threshold below $10^{-6}$ was not reached by any of the meta-analyses reporting a significant association (Table 2 and supplementary material). Similar NNT values were calculated for shared decision-making interventions $(\mathrm{NNT}=17.60,95 \% \mathrm{CI} 10.21-63.70)$ and staff training $(\mathrm{NNT}=16.26,95 \%$ CI 11.68-26.75), while the NNT for integrated care was 10.95 (95\% CI 5.30-70.63) (Fig. 2).

In all five meta-analyses, the $95 \%$ prediction intervals included the null value. Moderate to substantial heterogeneity $\left(I^{2}>50 \%\right)$ was observed only in the meta-analyses on adherence therapy and staff training interventions. Risk of small-study effects bias was not observed in any of the five meta-analyses, but excess of significance bias was detected in the meta-analysis on integrated care (Table 2).

\section{Umbrella review criteria and GRADE}

On the basis of these calculations, the strength of association was categorised as weak for shared decision-making and integrated care interventions, and suggestive for staff training interventions. According to GRADE, the credibility of evidence was moderate for shared decision-making and staff training interventions, low for integrated care and community treatment orders and very low for adherence therapy (supplementary material).

\section{Discussion}

The present umbrella review included 8554 participants from 23 studies (24 comparisons) contributing to 5 meta-analyses assessing the efficacy of interventions to reduce involuntary admissions and use of restraint in mental health services. On the basis of umbrella review criteria and GRADE, the evidence on the efficacy of staff training to reduce use of restraint was supported by the most robust evidence, followed by the evidence on the efficacy of shared decision-making interventions and integrated care to reduce involuntary admissions in adults with severe mental illness. By contrast, community treatment orders and adherence therapy had no effect on involuntary admission rates. According to GRADE, the credibility of evidence for staff training and shared decision-making interventions was moderate, with numbers needed to treat suggesting clinically relevant effect, especially in view of the pragmatic and hard nature of the outcome measures.

The beneficial effect of these interventions should be considered against potential risks associated with their implementation. For example, a risk of not providing effective treatments when needed may occur as a consequence of respecting the principle of autonomy when patients are less able to express their own will and preferences. ${ }^{73}$ Reduction of involuntary admissions or use of restraint might lead to greater use of medicines, with a potential increase in negative patient outcomes, ${ }^{74,75}$ including a theoretical negative effect on stigma where there is no proper care of people with 


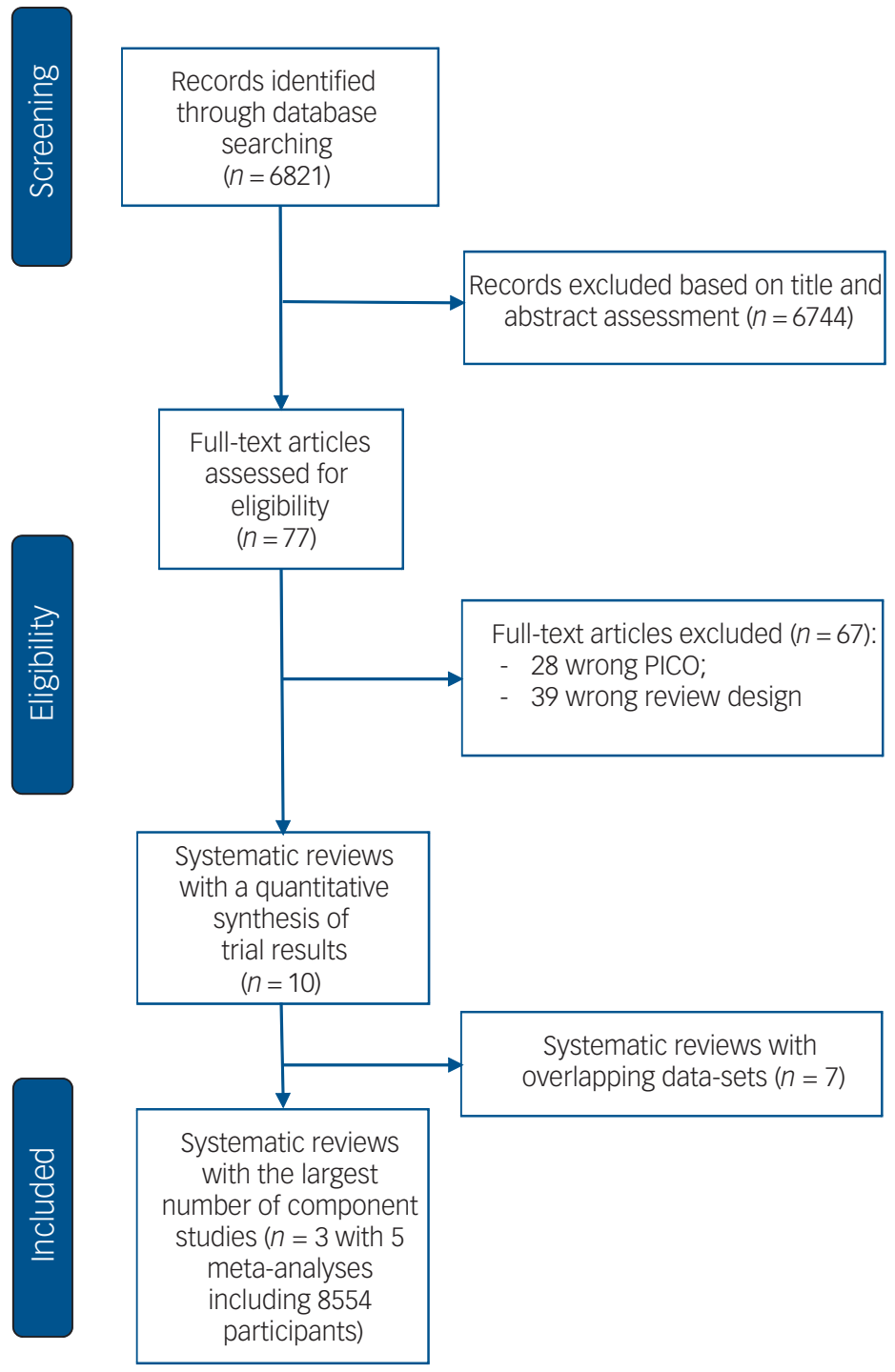

Fig. 1 PRISMA flow-diagram.

severe illness. Interestingly, the review of Molyneaux and colleagues, in addition to involuntary admissions, analysed the impact of shared decision-making interventions on voluntary admissions, which may be considered a proxy indicator of receiving care when needed. ${ }^{48}$ The finding that patients receiving shared decision-making interventions were admitted as often as the control group does not seem to give support to this potential risk, even though the provision of other forms of treatment, such as pharmacological or psychosocial interventions, has not been investigated.

\section{Implications for implementation}

Important implications for implementation can be drawn from these considerations. A first aspect is that these interventions have been developed to be used in the context of formal settings, that is in the context of existing mental health systems with a community-based organisation of mental healthcare. ${ }^{4}$ In addition to the many benefits of community-based and primary care and support, such services may reduce the need for hospital admission. ${ }^{11,76}$ Another prerequisite is the presence of legislative measures and policies aiming at operationalising a rights-based approach to decision-making. ${ }^{3,11,77,78}$ For these reasons, results may hardly be applied to contexts where detention, chaining and violent treatment occur outside any legislative framework. ${ }^{77}$ In some countries, for example, human rights abuses have been documented in a diverse range of treatment settings, including state hospitals, rehabilitation centres and other types of formal facility. ${ }^{1,2}$ Results may also hardly be applied to contexts where human rights abuses occur in non-formal settings such as spiritual healing centres and prayer camps. ${ }^{1,2}$

A second aspect is that the lack of effectiveness of community treatment orders makes a radical rethinking of the use of this intervention essential, particularly as it is included in the legislation and policy of many countries, with the expectation that it would contribute to avoiding compulsory admissions to hospital and enhance engagement in the community.

Within a general legislative, policy and organisational framework, implementing specific interventions to reduce coercive treatment would probably require their inclusion in existing guidelines for mental health conditions. The present umbrella review provides the background evidence for such an inclusion. We found that the evidence base is still not optimal, especially in terms of strength of associations, but it is nevertheless suggestive that coercive treatment may be reduced without major shortcomings. The WHO mhGAP Intervention Guide, for example, recommends a number of communication skills to create an environment that facilitates 


\begin{tabular}{|c|c|c|c|c|c|c|c|c|}
\hline $\begin{array}{l}\text { Intervention } \\
\text { group }\end{array}$ & $\begin{array}{l}\text { Study, by first- } \\
\text { author name }\end{array}$ & $\begin{array}{l}\text { Follow- } \\
\text { up, } \\
\text { months }\end{array}$ & Setting (country) & Population & Intervention characteristics & Outcome & $\begin{array}{l}n / N \text { with the outcome } \\
\text { in experimental } \\
\text { group }\end{array}$ & $\begin{array}{l}n / N \text { with the } \\
\text { outcome in } \\
\text { control group }\end{array}$ \\
\hline \multirow[t]{6}{*}{$\begin{array}{l}\text { Shared decision- } \\
\text { making }\end{array}$} & $\begin{array}{l}\text { Papageorgiou } \\
(2002)^{54}\end{array}$ & 12 & In-patients (UK) & $\begin{array}{l}\text { In-patient receiving compulsory } \\
\text { psychiatric treatment }\end{array}$ & $\begin{array}{l}\text { Advance directives; patients completed a } \\
\text { booklet consisting of seven statements on } \\
\text { future preferences for treatment }\end{array}$ & Involuntary admissions & $15 / 79$ & $16 / 77$ \\
\hline & $\begin{array}{l}\text { Henderson } \\
(2004)^{50}\end{array}$ & 15 & Out-patients (UK) & $\begin{array}{l}\text { Psychotic illness or non-psychotic } \\
\text { bipolar disorder }\end{array}$ & $\begin{array}{l}\text { Joint crisis plans consisting of indicators for } \\
\text { relapse and treatment preferences. Crisis } \\
\text { plan held by patient and the service they } \\
\text { belong to, and disseminated to anyone else } \\
\text { the patient specifies }\end{array}$ & Involuntary admissions & $10 / 80$ & $21 / 80$ \\
\hline & $\begin{array}{l}\text { Thornicroft } \\
(2013)^{52}\end{array}$ & 18 & Out-patients (UK) & Relapsing psychotic illness & $\begin{array}{l}\text { Joint crisis plan facilitated by a psychiatric nurse } \\
\text { and developed with the patient, their care } \\
\text { coordinator and psychiatrist, consisting of } \\
\text { indicators for relapse and treatment } \\
\text { preferences. Crisis plan held by patient and } \\
\text { the service they belong to, and disseminated } \\
\text { to anyone else the patient specifies }\end{array}$ & Involuntary admissions & $49 / 267$ & $56 / 280$ \\
\hline & $\begin{array}{l}\text { Ruchlewska } \\
\qquad(2014)^{51}\end{array}$ & 18 & $\begin{array}{l}\text { Out-patients (The } \\
\text { Netherlands) }\end{array}$ & Psychotic illness or bipolar disorder & $\begin{array}{l}\text { Crisis plan developed with the current patient } \\
\text { and clinician or a former patient, consisting } \\
\text { of early warning signs of crisis and future } \\
\text { treatment preferences. Held by patient and } \\
\text { in patients' records }\end{array}$ & Involuntary admissions & $27 / 138$ & $21 / 73$ \\
\hline & Lay $(2018)^{53}$ & 24 & $\begin{array}{l}\text { In-patients } \\
\text { (Switzerland) }\end{array}$ & $\begin{array}{l}\text { In-patient receiving psychiatric } \\
\text { treatment }\end{array}$ & $\begin{array}{l}\text { Crisis cards developed with patient and } \\
\text { facilitator listing treatment preferences and } \\
\text { early relapse signs, and 4-weekly ongoing } \\
\text { telephone monitoring plus individualised } \\
\text { psychoeducation sessions }\end{array}$ & Involuntary admissions & $21 / 75$ & $40 / 93$ \\
\hline & Lester $(2003)^{55}$ & 12 & Out-patients (UK) & Schizophrenia & $\begin{array}{l}\text { Patient-held record containing sections for } \\
\text { personal details, appointments, medication, } \\
\text { basic health information, personal and } \\
\text { emergency contact numbers, early warning } \\
\text { symptoms and a diary section to record } \\
\text { patient, carer and professional comments }\end{array}$ & Involuntary admissions & 1/92 & 4/99 \\
\hline \multirow[t]{3}{*}{$\begin{array}{l}\text { Community } \\
\text { treatment } \\
\text { orders }\end{array}$} & Swartz $(1999)^{56}$ & 12 & $\begin{array}{l}\text { Out-patients } \\
\text { (USA) }\end{array}$ & $\begin{array}{l}\text { Schizophrenia, schizoaffective disorder, } \\
\text { or other psychotic disorder or major } \\
\text { affective disorder }\end{array}$ & Community treatment order & Involuntary admissions & $56 / 129$ & $65 / 135$ \\
\hline & $\begin{array}{l}\text { Steadman } \\
\qquad(2001)^{57}\end{array}$ & 11 & $\begin{array}{l}\text { Out-patients } \\
\text { (USA) }\end{array}$ & $\begin{array}{l}\text { Schizophrenia, schizoaffective disorder, } \\
\text { or other psychotic disorder }\end{array}$ & Community treatment order & Involuntary admissions & $49 / 78$ & $42 / 64$ \\
\hline & Burns $(2013)^{58}$ & 12 & Out-patients (UK) & Psychosis & Community treatment order & Involuntary admissions & $59 / 167$ & $60 / 169$ \\
\hline \multirow[t]{2}{*}{$\begin{array}{r}\text { Adherence } \\
\text { therapy }\end{array}$} & Staring $(2010)^{59}$ & 12 & $\begin{array}{l}\text { Out-patients (The } \\
\text { Netherlands) }\end{array}$ & Severe mental illness & Treatment adherence therapy & Involuntary admissions & $1 / 54$ & $6 / 55$ \\
\hline & Priebe $(2013)^{60}$ & 12 & Out-patients (UK) & Severe mental illness & Financial incentives for adherence & Involuntary admissions & $15 / 78$ & $14 / 63$ \\
\hline
\end{tabular}




\begin{tabular}{|c|c|c|c|c|c|c|c|c|}
\hline $\begin{array}{l}\text { Intervention } \\
\text { group }\end{array}$ & $\begin{array}{l}\text { Study, by first- } \\
\text { author name }\end{array}$ & $\begin{array}{l}\text { Follow- } \\
\text { up, } \\
\text { months }\end{array}$ & Setting (country) & Population & Intervention characteristics & Outcome & $\begin{array}{l}n / N \text { with the outcome } \\
\text { in experimental } \\
\text { group }\end{array}$ & $\begin{array}{l}n / N \text { with the } \\
\text { outcome in } \\
\text { control group }\end{array}$ \\
\hline \multirow[t]{2}{*}{ Integrated care } & Johnson $(2005)^{61}$ & 6 & Out-patients (UK) & $\begin{array}{l}\text { People experiencing crises severe } \\
\text { enough for psychiatric hospital } \\
\text { admission }\end{array}$ & $\begin{array}{l}\text { Acute care, including a } 24 \mathrm{~h} \text { crisis resolution } \\
\text { team. Staff were available } 24 \mathrm{~h} \text { but on call } \\
\text { from home after } 22.00 \mathrm{~h}\end{array}$ & Involuntary admissions & $24 / 135$ & $32 / 125$ \\
\hline & $\begin{array}{l}\text { Sigrúnarson } \\
(2013)^{62}\end{array}$ & 12 years & $\begin{array}{r}\text { Out-patients } \\
\text { (Norway) }\end{array}$ & Psychosis & $\begin{array}{l}\text { Integrated treatment: patients and primary } \\
\text { caregivers received cognitive-behavioural } \\
\text { family communication and problem-solving } \\
\text { skills training, individual cognitive- } \\
\text { behavioural strategies for residual symptoms } \\
\text { and disability, and structured single-family } \\
\text { psychoeducation. Education in use of } \\
\text { medication and methods to improve } \\
\text { medication adherence was given }\end{array}$ & Involuntary admissions & $11 / 30$ & $12 / 20$ \\
\hline \multirow[t]{10}{*}{ Staff training } & Evans $(1997)^{69}$ & 6 & In-patients (USA) & Nursing home residents & $\begin{array}{l}\text { Restraint education with consultation and } 12 \mathrm{~h} / \\
\text { week consultation }\end{array}$ & Restraint use & $\begin{array}{l}\text { 27/152 (RE) 20/127 } \\
\text { (REC) }\end{array}$ & $83 / 184$ \\
\hline & Koczy $(2011)^{64}$ & 3 & $\begin{array}{l}\text { In-patients } \\
\text { (Germany) }\end{array}$ & Nursing home residents & Restraint education & Restraint use & $172 / 208$ & $114 / 125$ \\
\hline & Kopke $(2012)^{63}$ & 3 & $\begin{array}{l}\text { In-patients } \\
\text { (Germany) }\end{array}$ & Nursing home residents & $\begin{array}{l}\text { Restraint education and guidance ( } 90 \text { min } \\
\text { information programme, and 1-day training } \\
\text { workshop) }\end{array}$ & Restraint use & $423 / 1868$ & $525 / 1802$ \\
\hline & Pellfolk $(2010)^{66}$ & 6 & $\begin{array}{l}\text { In-patients } \\
\text { (Sweden) }\end{array}$ & Nursing home residents with dementia & $\begin{array}{l}\text { Education programme: } 2 \text { days of seminars, six } \\
30 \text { min videotaped lectures }\end{array}$ & Restraint use & $31 / 185$ & $55 / 165$ \\
\hline & Rovner $(1996)^{70}$ & 8 & In-patients (USA) & Nursing home residents with dementia & $\begin{array}{l}\text { Activity programme, guideline for psychotropic } \\
\text { drug management and educational rounds }\end{array}$ & Restraint use & $14 / 41$ & $20 / 28$ \\
\hline & Testad $(2010)^{65}$ & 6 & $\begin{array}{l}\text { In-patients } \\
\text { (Norway) }\end{array}$ & Nursing home residents with dementia & Restraint education and guidance & Restraint use & $8 / 75$ & $6 / 60$ \\
\hline & Testad $(2016)^{72}$ & 7 & $\begin{array}{l}\text { In-patients (The } \\
\text { Netherlands) }\end{array}$ & Nursing home residents & Restraint education and guidance & Restraint use & 9/73 & $7 / 114$ \\
\hline & Gulpers $(2013)^{71}$ & 4 & $\begin{array}{l}\text { In-patients (The } \\
\text { Netherlands) }\end{array}$ & Nursing home residents & Multicomponent staff-training intervention & Restraint use & 80/134 & $68 / 91$ \\
\hline & Huizing $(2006)^{68}$ & 2 & $\begin{array}{l}\text { In-patients (The } \\
\text { Netherlands) }\end{array}$ & Nursing home residents with dementia & $\begin{array}{l}\text { Restraint education and consultation: 2-month } \\
\text { education, five } 2 \mathrm{~h} \text { meetings and } \\
\text { consultation }\end{array}$ & Restraint use & $40 / 72$ & $38 / 54$ \\
\hline & Huizing (2009) $)^{67}$ & 2 & $\begin{array}{l}\text { In-patients (The } \\
\text { Netherlands) }\end{array}$ & $\begin{array}{l}\text { People in psychogeriatric nursing home } \\
\text { wards }\end{array}$ & $\begin{array}{l}\text { Restraint education and consultation: 2-month } \\
\text { education, five } 2 \mathrm{~h} \text { meetings, one } 90 \mathrm{~min} \\
\text { plenary session and consultation }\end{array}$ & Restraint use & $81 / 126$ & $69 / 115$ \\
\hline
\end{tabular}




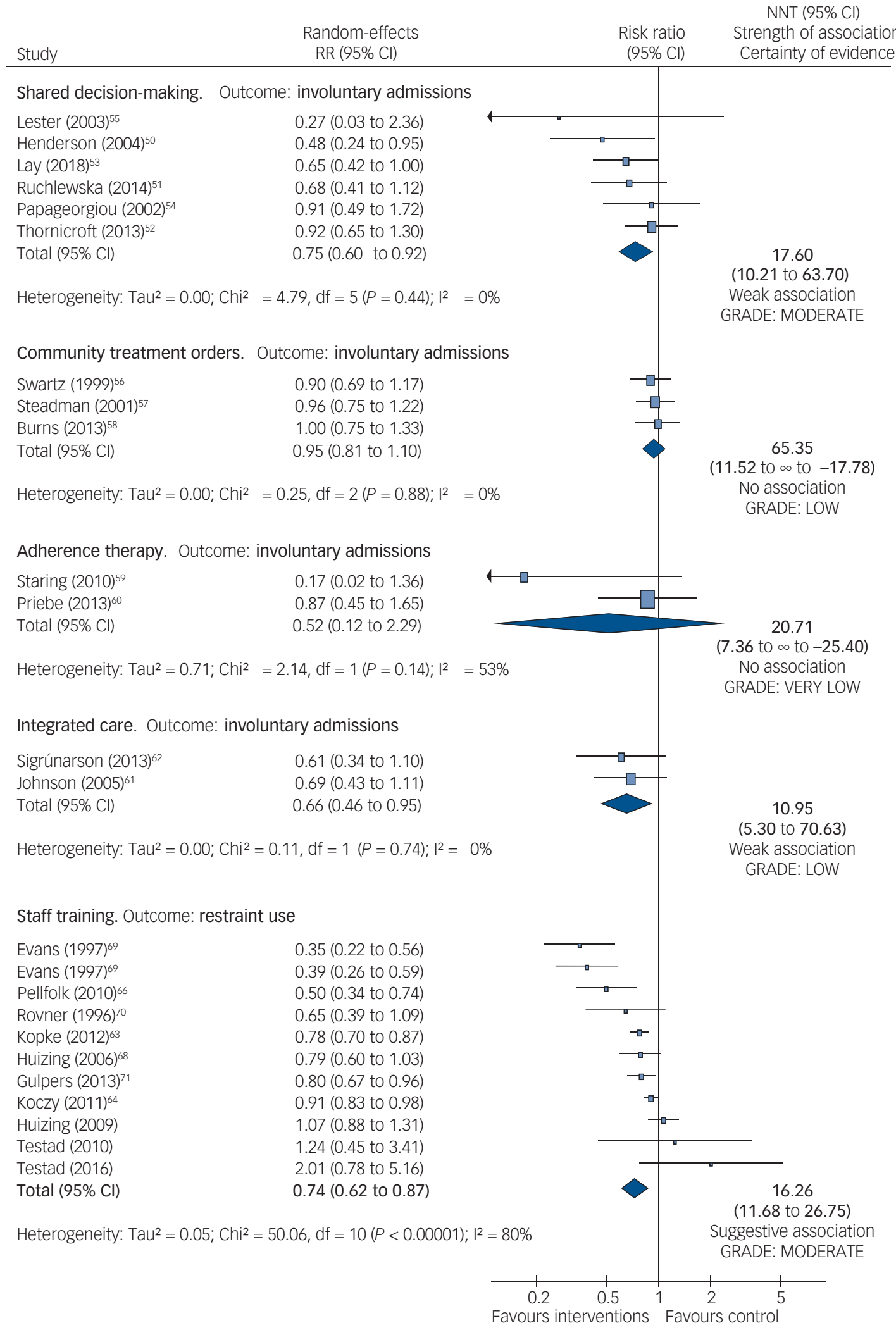

Fig. 2 Efficacy of interventions to reduce coercive treatment. RR, risk ratio; NNT, number needed to treat.

communication and shared decision-making. It generally suggests the promotion of the rights of people with mental health conditions in line with international human rights standards, although specific interventions with the primary aim of reducing coercive treatment are not included. ${ }^{79}$ The National Institute for Health and Care
Excellence (NICE) guideline on psychosis (www.nice.org.uk/ Guidance/CG178) does state that people have the right to be involved in discussions and to make informed decisions about their care, but this is reported as a general principle of care, and not as a structured group of interventions specifically developed 


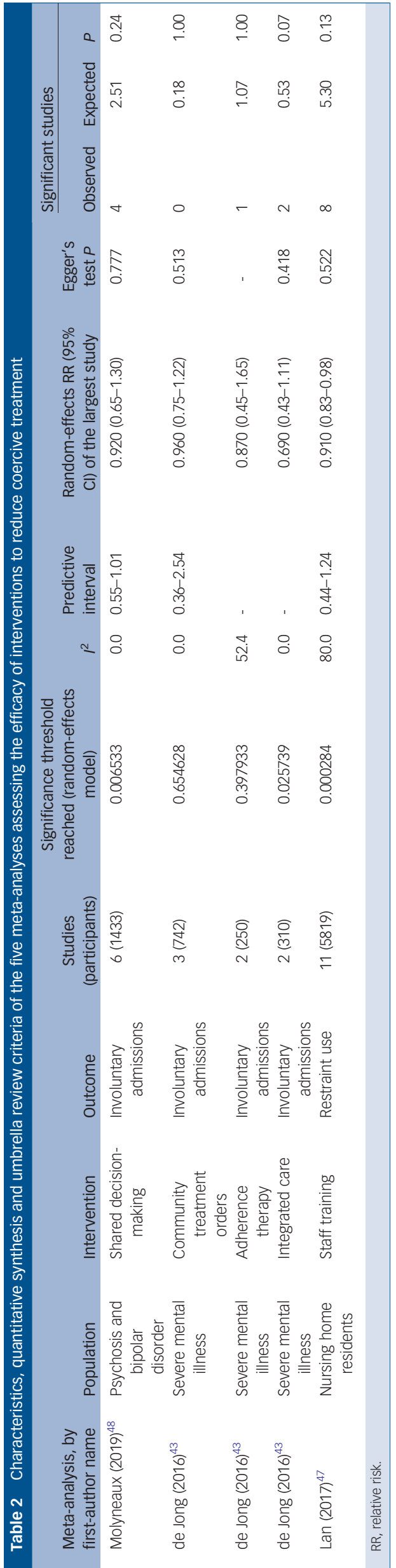

to reduce involuntary admissions. Operationalised and specific recommendations are more likely to be followed. Similarly, the NICE guideline on bipolar disorder (www.nice.org.uk/guidance/ CG185) encourages people with bipolar disorder to develop advance statements while their condition is stable as part of information and support strategies, but there is no mention of this as part of strategies to reduce coercive treatment. Minimising the use of restraint is reported by the NICE guideline on dementia (https://www.nice.org.uk/guidance/ng97), but how this should be achieved is not described. In this review we found suggestive evidence for a group of staff training interventions. It may also be important to link existing guidelines on the prevention and management of violence and aggression in mental healthcare ${ }^{80,81}$ with guidelines for specific mental health conditions. This could allow harmonisation of recommendations, giving due consideration to specific interventions to reduce coercive treatment.

\section{Limitations}

A general limitation of this umbrella review is that the effect on coercive practices of legislation, policies, service organisation models and population-level interventions, such as interventions based on advocacy, awareness-raising campaigns, moral persuasion and public engagement, cannot be assessed by means of randomised trials, and therefore these factors were not included in the systematic reviews that met criteria for this study. Similarly, complex multicomponent actions that are considered active ingredients of community mental health services, such as ensuring comprehensive responsibility in all phases of treatment, working on the environment and the social fabric, and fostering service accountability toward the community, ${ }^{82}$ are difficult to evaluate in formal studies. However, absence of randomised evidence for these interventions does not mean that they are ineffective. Law 180 in Italy remains a paradigmatic example of the potential impact of legislative measures on coercive practices, as its implementation determined a progressive dramatic decrease in the rates of involuntary admissions over the subsequent 40 years. ${ }^{83}$

Specific limitations of this umbrella review are those of the systematic reviews included, which, in turn, suffer from the limitations of the primary studies. The most frequently reported review shortcomings, detected by AMSTAR 2, were lack of a review protocol describing review methods prior to the conduct of the review, lack of information on funding and lack of a thorough discussion of between-study heterogeneity. Heterogeneity may be explained by differences in the details of the interventions, which may be considerable, and by the contexts in which the individual studies were conducted, which may vary greatly in terms of mental health laws, mental health and social care policies, resources and service configurations, and local social and cultural attitudes. Additional limitations refer to the umbrella review methodology, as this approach is based on statistical re-analysis of meta-analyses. By definition, therefore, umbrella reviews include only systematic reviews that applied a quantitative approach to data presentation, while systematic reviews providing qualitative descriptions of the included studies, without applying meta-analytic techniques, are excluded. Related to this, recently published primary studies might exist that have not been covered by the included meta-analyses. Another limitation is the narrow focus on involuntary admissions and use of restraint as main outcome measures. Although these are hard outcome measures, coercive treatment generally involves a broader range of implicit or explicit forms of pressure to accept certain treatments. ${ }^{4}$ The absence of studies from low- and middleincome countries (LMICs), where there is also widespread use of coercive treatment, is another important limitation of the existing literature. 


\section{Implications for research}

In terms of implications for research, the present review suggests the need for further studies on shared decision-making interventions, aiming to increase the precision of the overall estimate and strength of association, in view of the finding that the largest study included in the analysis ${ }^{84}$ highlighted a non-significant trend in favour of the intervention. Additionally, integrated care interventions, which included a crisis resolution team in one study, and a team providing cognitive-behavioural strategies and structured single-family psychoeducation in another, showed promising overall point estimates, but with wide confidence intervals, so the addition of new studies will probably substantially increase the strength and credibility of the evidence. We also note that studies on staff training interventions to prevent use of restraint were conducted in long-term facilities, nursing homes in most cases. A gap in knowledge therefore exists, as currently we do not know whether staff training may have similar beneficial effects on the use of restraint in acute inpatient psychiatric wards. ${ }^{85,86}$ We do have the first clinical trial, however, showing that training of traditional/faith healers, as well as a structured programme of collaboration with biomedical services, can dramatically reduce coercive practices in non-formal treatment settings. ${ }^{87}$

Further research is also needed on the potential impact of other interventions that may be particularly appropriate for reducing coercive treatment, such as peer-delivered mental healthcare, ${ }^{88-91}$ domiciliary interventions, ${ }^{92}$ open dialogue approaches, ${ }^{93}$ online, social media and mobile technologies, ${ }^{94}$ and the clubhouse ${ }^{95}$ and circle of care models. ${ }^{96}$ More generally, studies assessing the efficacy of interventions to reduce coercive treatment should always include clinical outcomes such as psychopathology status, use of pharmacological and non-pharmacological treatments, and use of voluntary admissions, in order to better describe whether the provision of these interventions is associated with decreased access to effective care. Future studies could benefit from more systematic mapping of contextual factors, as they may act as powerful effect modifiers. As frameworks for mapping of contextual variation across settings have been developed, ${ }^{97}$ their systematic use could allow future syntheses of what works, how and in what setting. Patient-rated and patient-generated outcome measures valued by patients should also be included. These studies should be conducted in formal and non-formal settings at different levels of economic development, including LMICs, so that legislative, policy, cultural and contextual factors can be taken into due consideration as potential determinants of intervention implementability and outcome.

Even though treatment guidelines may be extremely helpful in promoting the implementation of less coercive practices, we acknowledge that individual, stand-alone interventions may not be sufficient. To optimise uptake in clinical practice, a more general cultural change is probably needed. ${ }^{3,11}$ In particular, efforts should be dedicated to increasing participation in individual treatment choices, in policy and legislative decisions, and in general theoretical discussions, of a much broader range of stakeholders, including different groups of people with mental health conditions, family members, mental health professionals with clinical experience, scholars and experts in mental health legislation and policy. ${ }^{98}$ Finally, a profound reorientation in attitudes of professionals is necessary if practice is to change.

Corrado Barbui (D), Professor of Psychiatry, World Health Organization Collaborating Centre for Research and Training in Mental Health and Service Evaluation, Department of Neuroscience, Biomedicine and Movement Sciences, Section of Psychiatry, University of Verona, Italy; Marianna Purgato, PhD, World Health Organization Collaborating Centre for Research and Training in Mental Health and Service Evaluation, Department of Neuroscience, Biomedicine and Movement Sciences, Section of Psychiatry, University of Verona, Italy; Jibril Abdulmalik, MSc, World Health Organization Collaborating Centre for Research and Training in Mental Health, Neurosciences and Substance Abuse,
Department of Psychiatry, College of Medicine, University of Ibadan, Nigeria; José Miguel Caldas-de-Almeida, Professor of Psychiatry, Lisbon Institute of Global Mental Health, Comprehensive Health Research Centre, Nova Medical School, Nova University of Lisbon, Portugal; Julian Eaton, MRCPsych, Centre for Global Mental Health, London School of Hygiene and Tropical Medicine, UK; and CBM Global, Laudenbach, Germany; Oye Gureje, Professor of Psychiatry, World Health Organization Collaborating Centre for Research and Training in Mental Health, Neurosciences and Substance Abuse, Department of Psychiatry, College of Medicine, University of Ibadan, Ibadan, Nigeria; Charlotte Hanlon (D. PhD, King's College London, Institute of Psychiatry, Psychology and Neuroscience, Health Service and Population Research Department, Centre for Global Mental Health, UK; and WHO Collaborating Centre for Mental Health Research and Capacity Building, Department of Psychiatry, School of Medicine, College of Health Sciences, Addis Ababa University; and Centre for Innovative Drug Development and Therapeutic Trials for Africa (CDT-Africa), College of Health Sciences, Addis Ababa University, Ethiopia; Michela Nosè, PhD, World Health Organization Collaborating Centre for Research and Training in Mental Health and Service Evaluation, Department of Neuroscience, Biomedicine and Movement Sciences, Section of Psychiatry, University of Verona, Italy; Giovanni Ostuzzi, PhD, World Health Organization Collaborating Centre for Research and Training in Mental Health and Service Evaluation, Department of Neuroscience, Biomedicine and Movement Sciences, Section of Psychiatry, University of Verona, Italy; Benedetto Saraceno, MD, Lisbon Institute of Global Mental Health, Comprehensive Health Research Centre, Nova Medical School, Nova University of Lisbon, Portugal; Shekhar Saxena, Professor of the Practice of Global Mental Health, Global Health and Population, Harvard TH Chan School of Public Health, Boston, USA;

Federico Tedeschi, PhD, World Health Organization Collaborating Centre for Research and Training in Mental Health and Service Evaluation, Department of Neuroscience, Biomedicine and Movement Sciences, Section of Psychiatry, University of Verona, Italy: Graham Thornicroft, Professor of Psychiatry, Centre for Global Mental Health and Centre for Implementation Science, Institute of Psychiatry, Psychology and Neuroscience, King's College London, UK.

Correspondence: Professor Corrado Barbui. Email: corrado.barbui@univr.it

First received 4 May 2020, final revision 16 Jun 2020, accepted 5 Jul 2020

\section{Supplementary material}

Supplementary material is available online at http://doi.org/10.1192/bjp.2020.144.

\section{Data availability}

All data included in this umbrella review were extracted from publicly available systematic reviews.

\section{Author contributions}

C.B. and M.P. designed the study. C.B. drafted the manuscript. M.P., M.N., G.O. and F.T. contributed to the database preparation and double check. C.B. and M.P. did data analyses. J.A., J.M.C.-d.-A., J.E., O.G., C.H,. B.S., S.S. and G.T. critically revised the manuscript. All authors commented on, revised and approved the draft and final manuscript.

\section{Declaration of interest}

C.B. M.P. and F.T. receive support from the European Commission, grant agreement number 779255 'RE-DEFINE: Refugee Emergency: DEFining and Implementing Novel Evidence-based psychosocial interventions'. G.T. is supported by the National Institute for Health Research (NIHR) Collaboration for Leadership in Applied Health Research and Care (CLAHRC) South London and by the NIHR Applied Research Centre (ARC) at King's College London NHS Foundation Trust and the NIHR Applied Research Unit. G.T. receives support from the National Institute of Mental Health of the National Institutes of Health under award number R01MH100470 (Cobalt study). G.T. is supported by the UK Medical Research Council in relation the Emilia (MR/S001255/1) and Indigo Partnership (MR/R023697/1) awards. C.H. receives support from AMARI as part of the DELTAS Africa Initiative (DEL-15-01). G.T. and C.H. are funded by the National Institute of Health Research (NIHR) Global Health Research Unit on Health system Strengthening in Sub-Saharan Africa, King's College London (GHRU 16/136/54) using UK aid from the UK government. The views expressed in this publication are those of the authors and not necessarily those of the NIHR or the Department of Health and Social Care.

ICMJE forms are in the supplementary material, available online at http://doi.org/10.1192/ bjp.2020.144.

\section{References}

1 Ssengooba M, Barriga SR, Dufka C, Peligal R. "Like a Death Sentence": Abuses against Persons with Mental Disabilities in Ghana. Human Rights Watch, 2012.

2 Human Rights Watch. Nigeria: People with Mental Health Conditions Chained, Abused. Human Rights Watch, 2019.

3 Sashidharan SP, Mezzina R, Puras D. Reducing coercion in mental healthcare. Bull World Health Organ 2019; 28: 1-8.

4 Gooding P, McSherry B, Roper C. Preventing and reducing 'coercion' in mental health services: an international scoping review of English-language studies. 
Acta Psychiatr Scand [Epub ahead of print] 17 Jan 2020. Available from: https:// doi.org/10.1111/acps.13152.

5 weich S, McBride O, Twigg L, Duncan C, Keown P, Crepaz-Keay D, et al. Variation in compulsory psychiatric inpatient admission in England: a crossclassified, multilevel analysis. Lancet Psychiatry 2017; 4: 619-26.

6 de Stefano A, Ducci G. Involuntary admission and compulsory treatment in Europe: an overview. Int J Ment Health 2008; 37: 10-21.

7 Sashidharan SP, Saraceno B. Is psychiatry becoming more coercive? BMJ 2017; 357: j2904.

8 Broer J, Wierdsma Al, Mulder CL. [Regional differences in compulsory treatment in mental health care in the Netherlands during 2013-2017]. Tijdschr Psychiatr 2020; 62: 104-13.

9 Broer J, Mooij CF, Quak J, Mulder CL. [Continuous increase in community treatment orders and compulsory admissions in the Netherlands, 2003-2017]. Ned Tijdschr Geneeskd 2018; 162: D2454.

10 Freeman MC, Kolappa K, de Almeida JM, Kleinman A, Makhashvili N, Phakathi $\mathrm{S}$, et al. Reversing hard won victories in the name of human rights: a critique of the General Comment on Article 12 of the UN Convention on the Rights of Persons with Disabilities. Lancet Psychiatry 2015; 2: 844-50.

11 Sugiura K, Mahomed F, Saxena S, Patel V. An end to coercion: rights and decision-making in mental health care. Bull World Health Organ 2020; 98: 52-8.

12 Hammervold UE, Norvoll R, Aas RW, Sagvaag H. Post-incident review after restraint in mental health care -a potential for knowledge development, recovery promotion and restraint prevention. A scoping review. BMC Health Serv Res 2019; 19: 235.

13 Franke I, Busselmann M, Streb J, Dudeck M. Perceived institutional restraint is associated with psychological distress in forensic psychiatric inpatients. Front Psychiatry 2019; 10: 410.

14 Lasalvia A, Zoppei S, Van BT, Bonetto C, Cristofalo D, Wahlbeck K, et al. Global pattern of experienced and anticipated discrimination reported by people with major depressive disorder: a cross-sectional survey. Lancet 2013; 381: 55-62.

15 Puras D, Gooding P. Mental health and human rights in the 21st century. World Psychiatry 2019; 18: 42-3.

16 World Health Organization. WHO Handbook for Guideline Development, 2nd ed. WHO, 2014.

17 Barbui C, Dua T, van Ommeren M, Yasamy M, Fleischmann A, Clark N, et al. Challenges in developing evidence-based recommendations using the GRADE approach: the case of mental, neurological, and substance use disorders. PLOS Med 2010; 7(8): e1000322.

18 Guyatt G, Oxman AD, AkI EA, Kunz R, Vist G, Brozek J, et al. GRADE guidelines: 1. Introduction-GRADE evidence profiles and summary of findings tables. J Clin Epidemiol 2011; 64: 383-94.

19 Ioannidis JP. Integration of evidence from multiple meta-analyses: a primer on umbrella reviews, treatment networks and multiple treatments meta-analyses. CMAJ 2009; 181: 488-93.

20 Ioannidis J. Next-generation systematic reviews: prospective meta-analysis, individual-level data, networks and umbrella reviews. Br J Sports Med 2017; 51: $1456-8$.

21 Papatheodorou S. Umbrella reviews: what they are and why we need them. Eur J Epidemiol 2019; 34: 543-6.

22 Barbui C, Purgato M, Abdulmalik J, Acarturk C, Eaton J, Gastaldon C, et al Efficacy of psychosocial interventions for mental health outcomes in lowincome and middle-income countries: an umbrella review. Lancet Psychiatry 2020; 7: 162-72.

23 Solmi M, Correll CU, Carvalho AF, Ioannidis JPA. The role of meta-analyses and umbrella reviews in assessing the harms of psychotropic medications: beyond qualitative synthesis. Epidemiol Psychiatr Sci 2018; 27: 537-42.

24 Patel V, Saxena S, Lund C, Thornicroft G, Baingana F, Bolton P, et al. The Lancet Commission on global mental health and sustainable development. Lancet 2018; 392: 1553-98.

25 Moher D, Liberati A, Tetzlaff J, Altman DG. Preferred reporting items for systematic reviews and meta-analyses: the PRISMA statement. BMJ 2009; 339 b2535.

26 Shea BJ, Reeves BC, Wells G, Thuku M, Hamel C, Moran J, et al. AMSTAR 2: a critical appraisal tool for systematic reviews that include randomised or non-randomised studies of healthcare interventions, or both. BMJ 2017; 358 j4008.

27 DerSimonian R, Laird N. Meta-analysis in clinical trials. Control Clin Trials 1986 7: $177-88$

28 Furukawa TA. From effect size into number needed to treat. Lancet 1999; 353 1680.

29 Higgins JP, Thompson SG, Spiegelhalter DJ. A re-evaluation of random-effects meta-analysis. J R Stat Soc Ser A Stat Soc 2009; 172: 137-59.

30 Cochran WG. The combination of estimates from different experiments. Biometrics 1954; 10: 101-29.
31 Higgins JP, Green S. Cochrane Handbook for Systematic Reviews of Interventions Version 5.1.0. Cochrane Collaboration, 2011.

32 Sterne JA, Sutton AJ, Ioannidis JP, Terrin N, Jones DR, Lau J, et al. Recommendations for examining and interpreting funnel plot asymmetry in meta-analyses of randomised controlled trials. BMJ 2011; 343: d4002.

33 Egger M, Davey SG, Schneider M, Minder C. Bias in meta-analysis detected by a simple, graphical test. BMJ 1997; 315: 629-34.

34 Ioannidis JP, Trikalinos TA. An exploratory test for an excess of significant findings. Clin Trials 2007; 4: 245-53.

35 Lubin JH, Gail MH. On power and sample size for studying features of the relative odds of disease. Am J Epidemiol 1990; 131: 552-66.

36 Dragioti E, Karathanos V, Gerdle B, Evangelou E. Does psychotherapy work? An umbrella review of meta-analyses of randomized controlled trials. Acta Psychiatr Scand 2017; 136: 236-46.

37 Machado MO, Veronese N, Sanches M, Stubbs B, Koyanagi A, Thompson T, et al. The association of depression and all-cause and cause-specific mortality: an umbrella review of systematic reviews and meta-analyses. BMC Med 2018; 16: 112.

38 Guyatt $\mathrm{GH}$, Juniper EF, Walter SD, Griffith LE, Goldstein RS. Interpreting treatment effects in randomised trials. BMJ 1998; 316: 690-3.

39 Guyatt GH, Oxman AD, Kunz R, Vist GE, Falck-Ytter $Y$, schunemann HJ. What is "quality of evidence" and why is it important to clinicians? BMJ 2008; 336: 995-8.

40 Ayalon L, Lev S, Green O, Nevo U. A systematic review and meta-analysis of interventions designed to prevent or stop elder maltreatment. Age Ageing 2016; 45: 216-27.

41 Campbell LA, Kisely SR. Advance treatment directives for people with severe mental illness. Cochrane Database Syst Rev 2009; 1: CD005963.

42 Dahm KT, Leiknes KA, Husum TL, Kirkehei I, Hofmann B, Myhrhaug HT, et al. Interventions for Reducing Seclusion and Restraint in Mental Health for Adults. Knowledge Centre for the Health Services at The Norwegian Institute of Public Health (NIPH), 2012.

43 de Jong MH, Kamperman AM, Oorschot M, Priebe S, Bramer W, van de Sande R et al. Interventions to reduce compulsory psychiatric admissions: a systematic review and meta-analysis. JAMA Psychiatry 2016; 73: 657-64.

44 Farrelly S, Gill EB, Clare F, Elizabeth B, Richard L, Claire H. User held personalised information for routine care of people with severe mental illness. Cochrane Database Syst Rev 2013; 10: CD001711.

45 Kisely S, Hall K. An updated meta-analysis of randomized controlled evidence for the effectiveness of community treatment orders. Can J Psychiatry 2014; 59: 561-4.

46 Kisely SR, Campbell LA, O'Reilly R. Compulsory community and involuntary outpatient treatment for people with severe mental disorders. Cochrane Database Syst Rev 2017; 3: CD004408.

47 Lan SH, Lu LC, Lan SJ, Chen JC, Wu WJ, Chang SP, et al. Educational intervention on physical restraint use in long-term care facilities: systematic review and meta-analysis. Kaohsiung J Med Sci 2017; 33: 411-21.

48 Molyneaux E, Turner A, Candy B, Landau S, Johnson S, Lloyd-Evans B. Crisisplanning interventions for people with psychotic illness or bipolar disorder: systematic review and meta-analyses. BJPSych Open 2019; 5: e53.

49 Stovell D, Morrison AP, Panayiotou M, Hutton P. Shared treatment decisionmaking and empowerment-related outcomes in psychosis: systematic review and meta-analysis. Br J Psychiatry 2016; 209: 23-8.

50 Henderson C, Flood C, Leese M, Thornicroft G, Sutherby K, Szmukler G. Effect of joint crisis plans on use of compulsory treatment in psychiatry: single blind randomised controlled trial. BMJ 2004; 329: 136

51 Ruchlewska A, Wierdsma Al, Kamperman AM, van der Gaag M, Smulders R, Roosenschoon BJ, et al. Effect of crisis plans on admissions and emergency visits: a randomized controlled trial. PLOS One 2014; 9(3): e91882.

52 Thornicroft G, Farrelly S, Szmukler G, Birchwood M, Waheed W, Flach C, et al. Clinical outcomes of Joint Crisis Plans to reduce compulsory treatment for people with psychosis: a randomised controlled trial. Lancet 2013; $\mathbf{3 8 1}$ 1634-41.

53 Lay B, Kawohl W, Rossler W. Outcomes of a psycho-education and monitoring programme to prevent compulsory admission to psychiatric inpatient care: a randomised controlled trial. Psychol Med 2018; 48: 849-60.

54 Papageorgiou A, King M, Janmohamed A, Davidson O, Dawson J. Advance directives for patients compulsorily admitted to hospital with serious mental illness: randomised controlled trial. Br J Psychiatry 2002; 181: 513-9.

55 Lester $\mathrm{H}$, Allan T, Wilson S, Jowett S, Roberts L. A cluster randomised controlled trial of patient-held medical records for people with schizophrenia receiving shared care. Br J Gen Pract 2003; 53: 197-203.

56 Swartz MS, Swanson JW, Wagner HR, Burns BJ, Hiday VA, Borum R. Can involuntary outpatient commitment reduce hospital recidivism? Findings from a randomized trial with severely mentally ill individuals. Am J Psychiatry 1999; 156: $1968-75$ 
57 Steadman HJ, Gounis K, Dennis D, Hopper K, Roche B, Swartz M, et al. Assessing the New York City involuntary outpatient commitment pilot program. Psychiatr Serv 2001; 52: 330-6.

58 Burns T, Rugkasa J, Molodynski A, Dawson J, Yeeles K, Vazquez-Montes M, et al. Community treatment orders for patients with psychosis (OCTET): a randomised controlled trial. Lancet 2013; 381: 1627-33.

59 Staring ABP, van der Gaag M, Koopmans GT, Selten JP, Van Beveren JM Hengeveld MW, et al. Treatment adherence therapy in people with psychotic disorders: randomised controlled trial. Br J Psychiatry 2010; 197: 448-55.

60 Priebe S, Yeeles K, Bremner S, Lauber C, Eldridge S, Ashby D, et al. Effectiveness of financial incentives to improve adherence to maintenance treatment with antipsychotics: cluster randomised controlled trial. BMJ 2013; 347: f5847.

61 Johnson S, Nolan F, Pilling S, Sandor A, Hoult J, McKenzie N, et al. Randomised controlled trial of acute mental health care by a crisis resolution team: the north Islington crisis study. BMJ 2005; 331: 599.

62 Sigrunarson V, Grawe RW, Morken G. Integrated treatment vs. treatment-asusual for recent onset schizophrenia; 12 year follow-up on a randomized controlled trial. BMC Psychiatry 2013; 13: 200.

63 Kopke S, Muhlhauser I, Gerlach A, Haut A, Haastert B, Mohler R, et al. Effect of a guideline-based multicomponent intervention on use of physical restraints in nursing homes: a randomized controlled trial. JAMA 2012; 307: 2177-84.

64 Koczy P, Becker C, Rapp K, Klie T, Beische D, Buchele G, et al. Effectiveness of a multifactorial intervention to reduce physical restraints in nursing home residents. J Am Geriatr Soc 2011; 59: 333-9.

65 Testad I, Ballard C, Bronnick K, Aarsland D. The effect of staff training on agitation and use of restraint in nursing home residents with dementia: a singleblind, randomized controlled trial. J Clin Psychiatry 2010; 71: 80-6.

66 Pellfolk TJ, Gustafson Y, Bucht G, Karlsson S. Effects of a restraint minimization program on staff knowledge, attitudes, and practice: a cluster randomized trial. J Am Geriatr SOC 2010; 58: 62-9.

67 Huizing AR, Hamers JP, Gulpers MJ, Berger MP. A cluster-randomized trial of an educational intervention to reduce the use of physical restraints with psychogeriatric nursing home residents. J Am Geriatr Soc 2009; 57: 1139-48.

68 Huizing AR, Hamers JP, Gulpers MJ, Berger MP. Short-term effects of an educational intervention on physical restraint use: a cluster randomized trial. $B M C$ Geriatr 2006; 6: 17

69 Evans LK, Strumpf NE, Allen-Taylor SL, Capezuti E, Maislin G, Jacobsen B. A clinical trial to reduce restraints in nursing homes. J Am Geriatr SOC 1997; 45 675-81.

70 Rovner BW, Steele CD, Shmuely Y, Folstein MF. A randomized trial of dementia care in nursing homes. J Am Geriatr SOC 1996; 44: 7-13.

71 Gulpers MJ, Bleijlevens MH, Ambergen T, Capezuti E, van RE, Hamers JP. Reduction of belt restraint use: long-term effects of the EXBELT intervention. J Am Geriatr Soc 2013; 61: 107-12.

72 Testad I, Mekki TE, Forland O, Oye C, Tveit EM, Jacobsen F, et al. Modeling and evaluating evidence-based continuing education program in nursing home dementia care (MEDCED): training of care home staff to reduce use of restraint in care home residents with dementia. A cluster randomized controlled trial. Int J Geriatr Psychiatry 2016; 31: 24-32.

73 Szmukler G. "Capacity", "best interests", "will and preferences" and the UN convention on the rights of persons with disabilities. World Psychiatry 2019; 18: $34-41$

74 Sacks MH, Walton MF. Seclusion and restraint as measures of the quality of hospital care: any exceptions? Psychiatr Serv 2014; 65: 1373-5.

75 Zaami S, Rinaldi R, Bersani G, Marinelli E. Restraints and seclusion in psychiatry: striking a balance between protection and coercion. Critical overview of international regulations and rulings. Riv Psichiatr 2020; 55: 16-23.

76 World Health Organization, World Organization of Family Doctors. Integrating Mental Health into Primary Care: A Global Perspective. WHO/Wonca, 2008.

77 Hanna F, Barbui C, Dua T, Lora A, van Regteren AM, Saxena S. Global mental health: how are we doing? World Psychiatry 2018; 17: 367-8.
78 Committee on the Rights of Persons with Disabilities. General Comment No. 7 (2018) on the Participation of Persons with Disabilities, Including Children with Disabilities, through their Representative Organizations, in the Implementation and Monitoring of the Convention. ONHCR, 2018 (www.ohchr.org/en/hrbodies/crpd/pages/gc.aspx).

79 World Health Organization. mhGAP Intervention Guide for Mental, Neurological and Substance Use Disorders in Non-Specialized Health Settings: Version 2.0. WHO, 2016.

80 National Institute for Health and Care Excellence. Violence and Aggression Short-Term Management in Mental Health, Health and Community Settings (NICE Guideline NG10). NICE, 2015.

81 Steinert T, Hirsch S. [German S3 guidelines on avoidance of coercion: prevention and therapy of aggressive behavior in adults]. Nervenarzt 2019: 91: 611-6.

82 Mezzina R. Community mental health care in Trieste and beyond: an "open door-no restraint" system of care for recovery and citizenship. J Nerv Ment Dis 2014: 202: 440-5.

83 Barbui C, Papola D, Saraceno B. The Italian mental health-care reform: public health lessons. Bull World Health Organ 2018; 96: 731-A.

84 Thornicroft G, Henderson C. Joint decision making and reduced need for compulsory psychiatric admission. JAMA Psychiatry 2016; 73: 647-8.

85 Allen DE, Fetzer S, Siefken C, Nadler-Moodie M, Goodman K. Decreasing physical restraint in acute inpatient psychiatric hospitals: a systematic review. J Am Psychiatr Nurses AssoC 2019; 25: 405-9.

86 Bak J, Brandt-Christensen M, Christensen M, Sestoft DM, Zoffmann V. Mechanical restraint - which interventions prevent episodes of mechanical restraint? A systematic review. Perspect Psychiatr Care 2011; 48: 83-94.

87 Gureje O, Appiah-Poku J, Kola L, Araya R, Chisholm D, Esan D, et al. The effect of collaborative care between traditional/faith healers and primary health care workers to improve psychosis outcome in Nigeria and Ghana (COSIMPO): a randomized controlled trial. Lancet 2020; in press.

88 Acri M, Hooley CD, Richardson N, Moaba LB. Peer models in mental health for caregivers and families. Community Ment Health J 2017; 53: 241-9.

89 Puschner B. Peer support and global mental health. Epidemiol Psychiatr SCi 2018; 27: 413-4

90 Pathare S, Kalha J, Krishnamoorthy S. Peer support for mental illness in India: an underutilised resource. Epidemiol Psychiatr Sci 2018; 27: 415-9.

91 Alvarez-Jimenez M, Gleeson JF, Rice S, Gonzalez-Blanch C, Bendall S. Online peer-to-peer support in youth mental health: seizing the opportunity. Epidemiol Psychiatr Sci 2016; 25: 123-6.

92 Gomis O, Palma C, Farriols N. Domiciliary intervention in psychosis: a systematic review. Actas Esp Psiquiatr 2017; 45: 290-302.

93 Lakeman R. The Finnish open dialogue approach to crisis intervention in psychosis: a review. Psychother Aust 2014; 20: 28-35.

94 Alvarez-Jimenez M, Alcazar-Corcoles MA, Gonzalez-Blanch C, Bendall S, McGorry PD, Gleeson JF. Online, social media and mobile technologies for psychosis treatment: a systematic review on novel user-led interventions. Schizophr Res 2014; 156: 96-106.

95 Battin C, Bouvet C, Hatala C. A systematic review of the effectiveness of the clubhouse model. Psychiatr Rehabil J 2016; 39: 305-12

96 Information and Privacy Commissioner of Ontario. Circle of Care: Sharing Personal Health Information for Health-Care. IPC, 2015

97 Pfadenhauer LM, Gerhardus A, Mozygemba K, Lysdahl KB, Booth A, Hofmann $B$, et al. Making sense of complexity in context and implementation: the Context and Implementation of Complex Interventions $(\mathrm{CICl})$ framework. Implement Sci 2017; 12(1): 21

98 Caldas de Almeida JM. The CRPD Article 12, the limits of reductionist approaches to complex issues and the necessary search for compromise. World Psychiatry 2019; 18: 46-7.
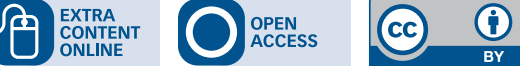